\section{Democracia e República plebeia}

John P. McCORMICK. Machiavellian democracy. Cambridge, Cambridge University Press, 2011. 252 páginas.

\section{Ricardo Silva}

Completados 500 anos da composição de $O$ Príncipe (1513) e do início da redação dos Discursos sobre a primeira década de Tito Livio - os Discorsi (1513-1519) -, o pensamento político de Maquiavel continua a ser objeto de vivo interesse dos teóricos da política. A despeito das inúmeras análises e interpretações já realizadas sobre o mestre florentino, suas ideias continuam estimulando alguns dos movimentos mais inovadores no debate teórico contemporâneo, a exemplo do recentemente publicado Machiavellian democracy, de John P. McCormick, professor de teoria política da Universidade de Chicago. Fruto de prolongada investigação sobre o pensamento político e constitucional de Maquiavel, o livro consolida e expande a interpretação prenunciada pelo autor em uma série de artigos e ensaios publicados ao longo da última década.

A contribuição de McCormick guarda uma relação tensa com a corrente interpretativa protagonizada por autores como Hans Baron (1961), J. G. A. Pocock (1975), Quentin Skinner (2002) e Maurizio Viroli (1998), defensores do restabelecimento da identidade republicana do pensamento de Maquiavel (Silva, 2010). Compreendendo-o como herdeiro direto do republicanismo clássico e principal fonte de inspiração do republicanismo moderno e contemporâneo, esses autores se insurgiram contra a visão que retratava o florentino como uma espécie de conselheiro de tiranos e "professor do mal” (Strauss, 1958). Embora considere a interpretação neorrepublicana de Maquiavel superior à interpretação tradicional, McCormick critica os autores supracitados por subestimarem a importância que o autor dos Discorsi atribuía aos setores populares e suas magistraturas na constituição e manutenção da liberdade pública. Ao não questionarem a suposta conformidade de Maquiavel com um conjunto de princípios refratários ao poder da plebe nas repúblicas - princípios compartilhados pela maioria dos republicanos clássicos e moder- nos, mas enfaticamente rejeitados por Maquiavel -, os intérpretes vinculados à "Escola de Cambridge" corroborariam, na atualidade, o viés aristocrático predominante na história do republicanismo.

Para McCormick, não se trata de postular a exclusão de Maquiavel da tradição republicana, mas de reconhecer plenamente seu papel de radical inovador no âmbito dessa vasta e polimorfa tradição. De Cícero a Guicciardini, de Harrington a Madison, de Rousseau a Montesquieu, podemos constatar a relação no mínimo ambígua - e frequentemente inamistosa - dos princípios republicanos com as práticas e as instituiçõos democráticas. McCormick sustenta que a inovação de Maquiavel consiste justamente em rejeitar a dimensão do republicanismo em que o governo popular é sempre preterido em favor de uma perspectiva aristocrática e senatorial. Como observou acertadamente Nadia Urbinati, em Machiavellian democracy, "McCormick quer reconciliar democracia e republicanismo", defendendo "um tipo democrático de republicanismo, em que a liberdade é baseada na atribuição de poder político aos socialmente desiguais" (Urbinati, 2011, p. 165).

Em seus sete capítulos, distribuídos em três partes, além de uma leitura contextualizada dos textos políticos de Maquiavel, o livro contém uma tentativa de aplicação do resultado dessa leitura nos debates da teoria democrática contemporânea. $\mathrm{Na}$ primeira parte, que compreende os capítulos 1 e 2, o autor dá relevo à teoria maquiaveliana dos conflitos sociais, indicando a importância de tal teoria tanto em $O$ Príncipe como nos Discorsi. Partindo da célebre constatação de Maquiavel sobre a inevitabilidade da existência de dois "humores" contrastantes em qualquer ordem sociopolítica, o do povo e o dos grandes, McCormick ilumina as conseqüências desse conflito de "classes" para o estabelecimento e a manutenção da liberdade nas repúblicas. $\mathrm{O}$ desejo dos ricos e poderosos de expandir seu domínio encontra-se em conflito com o desejo do povo de não ser dominado, e da necessidade de regulação desse conflito surgem as instituiçôes para o estabelecimento e a manutenção da liberdade. Sem deixar de registrar o ceticismo de Maquiavel acerca da pretensa superioridade moral inata e infalibilidade do julgamento popular, McCormick argumenta que o florentino considerava as predisposiçōes e a capacidade 
de julgamento dos cidadãos ordinários - ao menos quando reunidos em fóruns institucionalizados e regulados por leis - mais sintonizadas com preservação da liberdade do que as predisposiçōes das elites, sempre mais inclinadas ao exercício da dominação, à ambição desmedida e ao comportamento insolente.

Do ponto de vista da metodologia de análise histórica, McCormick dedica considerável esforço à contextualização dos enunciados de Maquiavel; o bastante para afastá-lo de conclusões enfraquecidas pelo anacronismo. Sua estratégia consiste em compreender os textos maquiavelianos à luz das audiências às quais eles se destinavam. As dedicatórias de O Príncipe, dos Discorsi e da História de Florença são indicações precisas dos destinatários das lições contidas nessas obras, público que Maquiavel procurava, ao mesmo tempo, instruir e persuadir. Não obstante tal esforço de contextualização histórica, o objetivo declarado do autor é recuperar em Maquiavel um acervo institucional apto a superar alguns dos graves dilemas das repúblicas contemporâneas, mormente "a crise de accountability" que permite aos "membros mais ricos da sociedade" o exercício "de uma excessiva influência sobre a lei e o processo decisório” (p. vii). A combinação entre a história do pensamento político e a teoria política contemporânea levou Andrew Rehfeld a considerar o livro de McCormick uma "trifecta" da teoria política, "por seu uso da história do pensamento político para descobrir algo sobre o passado com os olhos voltados à solução de problemas políticos contemporâneos" (Rehfeld, 2011, p. 227).

$\mathrm{Na}$ segunda parte do livro, o autor transita da análise da teoria maquiaveliana dos conflitos sociais para a análise das consequências institucionais que Maquiavel deriva da existência de tais conflitos. É sob essa orientação que emerge o modelo da democracia maquiaveliana, cuja forma institucional consiste basicamente de três elementos: 1) instituição de magistraturas e assembleias exclusivamente populares, dotadas de poder de veto e iniciativa legislativa; 2) instituição de um sistema de escolha de magistrados combinando sorteio e eleição; 3) instituição de mecanismos judiciais ("julgamentos políticos”) pelos quais os cidadãos comuns possam participar do julgamento de representantes e magistrados acusados de crimes políticos. Ao longo dos capítulos 3, 4 e 5, McCormick examina detalhadamente a visão de Maquiavel sobre o funcionamento dessas instituições na antiga república romana, bem como a falta que elas fizeram em Florença. O funcionamento desse modelo em Roma contribuiu para a preservação da liberdade por um longo período. Em Florença, ao contrário, onde o povo não encontrava meios institucionais para canalizar e desafogar sua ira contra o comportamento insolente das elites, os conflitos resultaram comumente em revoltas cruentas, por meios extraordinários, e apoios a prospectivos tiranos.

O tribunato romano é o exemplo mais bem acabado de uma instituição democrática de representação exclusiva da plebe. McCormick considera o tribunato a "peça central das prescrições de Maquiavel para o governo popular" (p. 6). Tão central que teria levado o florentino a propor algo semelhante em sua própria época, quando instado pelo cardeal Júlio de Medici a esboçar uma reforma das instituiçôes políticas de Florença. Em sua análise do texto do Discurso sobre as formas de governo de Florença, McCormick dá destaque para a proposta de Maquiavel de instituição dos proposti, "uma magistratura com poderes de veto e apelação que excluía os cidadãos mais proeminentes da república” (p. 8). Ao ressaltar a importância de instituiçōes similares ao tribunato romano, McCormick chama a atenção para a preferência de Maquiavel por um modelo de representação política setorial, em detrimento dos modelos universalistas, nos quais a dominação exercida pelos detentores de riqueza material e poder social tende a permanecer oculta no debate público.

Paralelamente à criação de magistraturas exclusivamente populares, a democracia maquiaveliana institui o mecanismo dos sorteios para a escolha de representantes e magistrados. Aqui, a inspiração de McCormick parece ser antes a democracia ateniense do que a república romana, embora tanto nesta última como nas cidades medievais e renascentistas a prática do sorteio estivesse ainda presente, ao contrário do que passou a ocorrer nas repúblicas modernas. $\mathrm{O}$ completo abandono do sorteio e a exclusividade assumida pelo mecanismo eleitoral para a escolha de representantes teriam acentuado o "efeito aristocrático" nos governos representativos 
contemporâneos, fenômeno exemplarmente examinado por Bernard Manin (1997).

Além da instituição de magistraturas exclusivamente populares e da introdução do sorteio para a constituição de representantes, a democracia maquiaveliana requer que se atribua ao conjunto dos cidadãos ordinários a prerrogativa de participar de julgamentos públicos de representantes e magistrados acusados de crimes políticos. Um dos instrumentos mais eficazes para promover a accountability dos detentores de cargos públicos é a extensão do direito de acusação a qualquer cidadão, tal como Maquiavel entendia ocorrer nos tempos da antiga república romana. Acusar, por certo, é diferente de caluniar: "Acusações devem ser apoiadas em evidências; se estas se provam inconvincentes ao povo, então o acusador será considerado um caluniador, que deve pois sofrer uma punição tão dura quanto aquela que pesa sobre a pessoa acusada" (p. 125). O direito de acusação é seguido pelo direito de participação direta de um número amplo de cidadãos comuns no julgamento dos acusados. Ao propor a inclusão dos populares no processo de acusação e julgamento de crimes políticos, Maquiavel procurava evitar que tal processo fosse controlado e manipulado pelos detentores de poder social e político, o que muitas vezes ocasionava, como em Florença, disputas facciosas intraelite, sempre prejudiciais ao interesse público. Além disso, a presença ativa do povo nos julgamentos políticos era um poderoso canal de vazão de suas insatisfações. Aqui, também, a república de Florença revela seu contraste e sua desvantagem em relação à antiga república romana. Como observa McCormick, "para Maquiavel, a ausência de procedimentos amplamente populares de acusação, julgamento e apelação legalmente estabelecidos foi uma das principais causas da instabilidade da república” florentina (p. 138).

Definida a forma institucional da democracia maquiaveliana, o autor volta-se aos problemas atuais da teoria democrática do novo republicanismo. Esse é o tema da terceira parte do livro, que compreende os capítulos 6 e 7. Observa-se aí a culminação do encontro entre a história das ideias e a teoria política contemporânea, que se realiza mediante uma abordagem simultaneamente crítica e propositiva. O capítulo 6 contém uma extensa crítica do modelo de democracia articulado pelo teórico neorrepublicano Philip Pettit, "o mais proeminente e intelectualmente formidável filósofo do 'republicanismo' atual" (p. 142). Como se sabe, Pettit desenvolve sua versão do republicanismo sob a influência da narrativa de Quentin Skinner sobre a história da concepção republicana de liberdade (Silva, 2008). $\mathrm{O}$ alvo das críticas de McCormick não é a teoria da liberdade como não dominação, principal contribuição de Pettit à teoria política contemporânea (Pettit, 1997). Afinal, não pode escapar a qualquer estudioso da dimensão democrática do republicanismo de Maquiavel a tese de que o desejo do povo de "não ser dominado" é a fonte mais confiável para a geração de meios de preservação da liberdade civil (cf. Discorsi, livro 1, capítulo 5). Embora não se detenha na crítica da formulação "filosófica" do conceito de liberdade como não dominação, McCormick investe sistematicamente contra o modelo institucional arquitetado por Pettit para a realização desse ideal de liberdade. Seu alvo é o modelo "eleitoral-contestatório", mediante o qual Pettit procura articular as instituições tradicionais da democracia eleitoral com um conjunto de mecanismos jurídico-institucionais pelos quais os cidadãos particulares e as minorias podem contestar leis e políticas governamentais que julgarem lesivas à manutenção da liberdade (Pettit, 1999). A maior debilidade desse modelo estaria em erigir uma institucionalidade democrática sobre a base de uma concepção estritamente jurídica (e filosófica) de povo. Nesse ponto, McCormick acusa Pettit de associar-se a uma perspectiva aristocrática do republicanismo, esvaziando a noção de povo de suas conotações sociológicas e obscurecendo o que Maquiavel procurava iluminar: a clivagem socioeconômica e política entre ricos e pobres. Assim, "ainda que o pensamento de Maquiavel sobre a liberdade coincida em importantes aspectos com a concepção indisputavelmente imponente de liberdade como não dominação, Maquiavel rejeita os arranjos institucionais marginalizadores do povo, característicos do republicanismo filosófico de Platão a Pettit” (p. 168).

No capítulo conclusivo de seu livro, McCormick desenvolve o que ele próprio apresenta como um "experimento mental" no campo do constitucionalismo, imaginando uma reforma da constitui- 
ção dos Estados Unidos qualificada pela instituição de uma espécie de tribunato com amplos poderes constitucionais. Trata-se de "uma proposta heurística orientada para um propósito crítico, não necessariamente e diretamente prático" (p. 183). Composto por 51 membros escolhidos por sorteio entre a parcela da população com renda familiar anual inferior a U\$ 345 mil, o que excluiria os $10 \%$ mais ricos da população dos Estados Unidos, o tribunato idealizado por McCormick assume as características de um novo poder, simétrico e competitivo em relação aos poderes tradicionais dos parlamentos nas repúblicas contemporâneas. Não é o caso, aqui, de elencar as regras de composição e as prerrogativas constitucionais de veto, sanção e iniciativa legislativa do tribunato norte-americano previstas por McCormick (pp. 183-185). É suficiente destacar o sentido geral da proposta. Para o autor, "no espírito do elogio de Maquiavel aos tribunos romanos e de sua aspiração dos proposti florentinos, os tribunos norte-americanos serviriam como uma 'guarda da liberdade' popularmente embasada dentro da República norte-americana” (p. 187).

É difícil exagerar o quanto o modelo da democracia maquiaveliana afasta-se das perspectivas predominantes na teoria democrática contemporânea. Nas democracias eleitorais de hoje, as particularidades sociais dissolvem-se em contato com a força niveladora do sufrágio universal. Os resultados das urnas recompõem abstratamente a unidade social, produzindo a ilusão (necessária?) de um povo uno e sociologicamente anônimo, real depositário da soberania na polity democrática. $\mathrm{O}$ modelo da democracia maquiaveliana rejeita essa operação de universalização e recusa o procedimento de abstração das determinações concretas das disposiçôes dos setores sociais fundamentais. O que resta é uma polity dividida, na qual a preservação da liberdade e a produção de igualdade resultarão do conflito social institucionalmente regulado entre as elites e o povo, entre o desejo de dominar e o de não ser dominado.

\section{BIBLIOGRAFIA}

BARON, Hans. (1961), "Machiavelli: the republican citizen and the author of The Prince". The
English Historical Review, 76 (299): 217-253.

MANIN, Bernard. (1997), The principles of representative government. Cambridge, Cambridge University Press.

MCcORMICK, John. (2011), Machiavellian democracy. Cambridge, Cambridge University Press.

PETTIT, Philip. (1997), Republicanism: theory of freedom and government. Oxford, Oxford University.

. (1999), "Republican freedom and contestatory democratization", in I. Shapiro e C. Hacker-Cordon (eds.). Democracy's value, Cambridge, Cambridge University Press.

POCOCK, John. (1975), The Machiavellian moment: florentine political thought and the Antlantic Republican traditition. Princeton, NJ, Princeton University Press.

REHFELD, Andrew. (2011), "Incentivize the powerful or empower the poor: thoughts on John McCormick's Machiavellian Democracy”. The Good Society, 20 (2): 226-239.

SILVA, Ricardo. (2008), "Liberdade e lei no neo-republicanismo de Skinner e Pettit". Lua Nova, 74: 151-194.

. (2010), "Maquiavel e o conceito de liberdade em três vertentes do novo republicanismo". Revista Brasileira de Ciências Sociais, 25 (72): 37-58.

SKINER, Quentin. (2002), Visions of politics. Vol. 2: Renaissance virtues. Cambridge, Cambridge University Press.

STRAUSS, Leo. (1958), Thoughts on Machiavelli. Glencoe, IL, Free Press.

URBINATI, Nadia. (2011), "Republicanism: democratic or popular?". The Good Society, 20 (2): 157-169.

VIROLI, Maurizio. (1998), Machiavelli. Oxford, Oxford University Press.

RICARDO SILVA

é professor do Programa de Pós-Graduação em Sociologia Política da Universidade Federal de Santa Catarina - UFSC. E-mail: <rsilva@cfh.ufsc.br>. 